\title{
A influência do estilo de aprendizagem no desempenho escolar e a percepção sobre interdisciplinaridade de discentes de uma escola pública profissionalizante
}

The influence of learning style on school performance and the perception of interdisciplinarity of students from a professionalizing public school

Januária Fonseca Matos

Coordenadoria da Área de Ciências Biológicas, Instituto Federal Minas Gerais, Campus Ouro Preto, Minas Gerais, Brasil.

januaria.matos@ifmg.edu.br - https://orcid.org/0000-0002-4183-4621

Wendel Coura-Vital

Departamento de Análises Clínicas, Escola de Farmácia, Universidade Federal de Ouro Preto. Ouro Preto, Minas Gerais, Brasil.

wendelcoura@ufop.edu.br - https://orcid.org/0000-0002-1434-7676

Elisângela Silva Pinto

Coordenadoria da Área de Física, Instituto Federal Minas Gerais, Campus Ouro Preto, Minas Gerais, Brasil.

elisangela.pinto@ifmg.edu.br - https://orcid.org/0000-0002-8531-2470

Recebido em 24 de abril de 2020

Aprovado em 05 de março de 2021

Publicado em 31 de julho de 2021

\section{RESUMO}

O conhecimento do estilo de aprendizagem dos estudantes possibilita ajustar a metodologia adotada pelos docentes, considerando-se que a diversidade e a flexibilidade são aspectos a serem observados no processo ensino-aprendizado e na formação de cidadãos conscientes. Somado a isso, a interdisciplinaridade conecta disciplinas distintas despertando o interesse dos estudantes. O objetivo deste estudo foi avaliar a influência do estilo de aprendizagem no desempenho escolar e a contribuição da interdisciplinaridade no processo de ensino, conforme a percepção dos discentes. Foram aplicados dois instrumentos, sendo um questionário para determinação do estilo de aprendizagem dos discentes e de seus professores de Biologia e Física e outro, na escala de Likert, para avaliar a percepção sobre interdisciplinaridade após aplicação de uma sequência didática sobre biofísica da respiração. Foram avaliados 32 discentes de uma turma de $2^{a}$ série de uma escola pública profissionalizante e os docentes das disciplinas de Biologia e Física. Foi observado que o estilo de aprendizagem geral da turma é, predominantemente, 


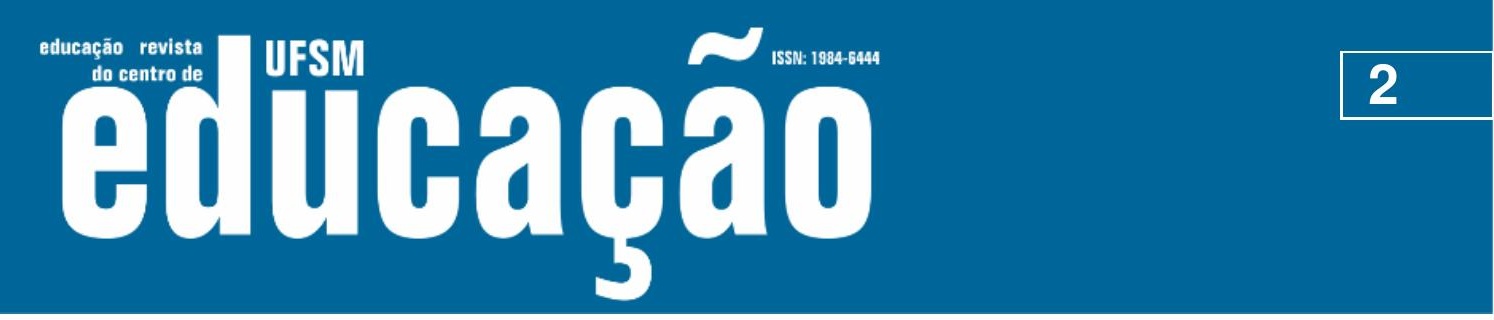

ISSN: 1984-6444 | http://dx.doi.org/10.5902/1984644443675

sensorial/visual/ativo e reflexivo/sequencial e coincide com o desses professores, corroborando para um bom desempenho escolar. Entretanto, no grupo de discentes que ficou em recuperação na primeira etapa do ano letivo, metade tem preferência pelo polo global, o que é discordante do estilo de aprendizagem de seus professores, que são sequenciais. Possivelmente, essa discordância teve algum impacto no aprendizado desses estudantes. Também foi verificado que, na percepção dos estudantes, as atividades interdisciplinares, especialmente práticas, facilitam a compreensão de um conteúdo. Esses achados permitem uma reflexão sobre como a prática cotidiana dos professores pode contribuir para o aprendizado.

Palavras-chave: Estilo de aprendizagem; Interdisciplinaridade; Biofísica.

\section{ABSTRACT}

The knowledge of the students' learning style makes it possible to adjust the methodology adopted by teachers considering that diversity and flexibility are aspects to be observed in the teaching-learning process and in the formation of conscious citizens. In addition, interdisciplinarity connects different disciplines, arousing the interest of students. The aim of this study was to evaluate the influence of the learning style on school performance and the contribution of interdisciplinarity in the teaching process, according to students' perception. Two instruments were applied, one questionnaire to determine the learning style of students and their Biology and Physics teachers and other, on the Likert scale, to assess the perception of interdisciplinarity after applying a didactic sequence on biophysics of breathing. 32 students from a 2nd grade class at a public professional school and Biology and Physics teachers were evaluated. It was observed that general learning style of the class is sensory/visual/active and reflective/sequential and coincides with that of these teachers, corroborating for a good school performance. However, in the group of students who were recovering in the first stage of the school year, half have a preference for the global pole, which is at variance with the learning style of their teachers, who are sequential. Possibly, this disagreement had some impact on the learning of these students. It was also found that, in the students' perception, interdisciplinary activities, practical in special, facilitate the understanding of a content. These findings allow a reflection on how the teachers' daily practice can contribute to learning.

Keywords: Learning style; Interdisciplinarity; Biophysics. 


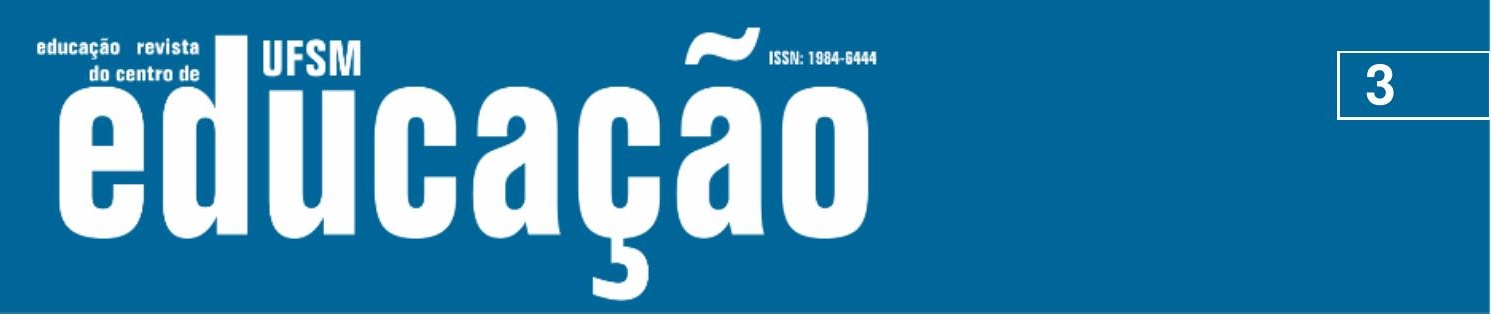

ISSN: 1984-6444 | http://dx.doi.org/10.5902/1984644443675

\section{Introdução}

Cada indivíduo possui um estilo próprio para aprender fatos novos (SCHMITT; DOMINGUES, 2016). Segundo Silva (2006), os estilos de aprendizagem relacionam-se à forma particular de adquirir conhecimento, habilidades ou atitudes, seja através da experiência ou de estudos.

É comum estudantes apresentarem baixo desempenho ou maior rejeição por determinada disciplina não necessariamente por ser mais difícil, mas por exigir abordagens diferenciadas no seu ensino. Uma hipótese seria uma possível incompatibilidade entre os estilos de aprendizagem da maioria dos alunos e os estilos de ensinar dos professores. Uma vez que o estilo de aprendizagem reflete o próprio estilo de ensinar, essa incompatibilidade reflete-se em poucas variações metodológicas e, muitas vezes, baixo rendimento escolar (PEREIRA; VIEIRAJÚNIOR, 2013). Sendo assim, conhecer os estilos de aprendizagem dos discentes é crucial para os professores, pois norteia a sua conduta pedagógica em sala de aula, permitindo um maior aproveitamento do potencial de aprendizado dos alunos.

$\mathrm{Na}$ literatura, encontram-se vários instrumentos para mensuração dos diferentes estilos de aprender. Um desses instrumentos é o chamado N-ILS (New Index of Learning Styles) proposto por Vieira-Júnior (2012), um teste composto por 20 questões objetivas. O N-ILS é uma versão do teste original de Felder e Soloman (1991), adaptada ao contexto brasileiro. O modelo é composto por quatro dimensões que representam as etapas da aprendizagem, sendo que cada dimensão possui dois polos. Dependendo da maneira como o estudante aprende, ele tende a um polo em cada dimensão. As dimensões e seus respectivos polos são: Percepção (sensorial ou intuitivo); Entrada (visual ou verbal); Processamento (ativo ou reflexivo); e Entendimento (sequencial ou global) (CURY, 2000; VIEIRA JÚNIOR, 2012).

No Brasil, as Diretrizes Curriculares Nacionais para o Ensino Médio vigentes (Resolução CNE/CEB no 3/98, fundamentada no Parecer CNE/CEB no 15/98) destacam, de forma especial, a interdisciplinaridade, assumindo o princípio de que 


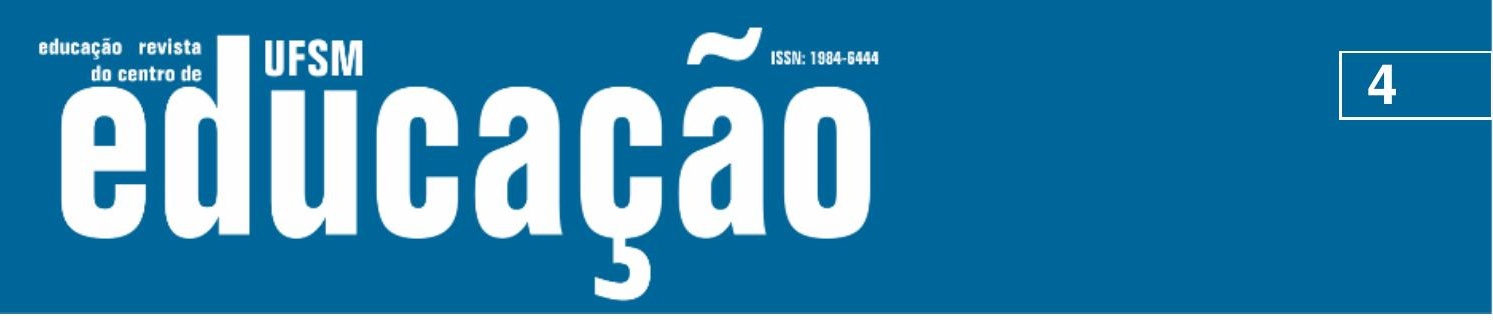

ISSN: 1984-6444 | http://dx.doi.org/10.5902/1984644443675

"todo conhecimento mantém um diálogo permanente com outros conhecimentos", e que:

O ensino deve ir além da descrição e constituir nos estudantes a capacidade de analisar, explicar, prever e intervir, objetivos que são mais facilmente alcançáveis se as disciplinas, integradas em áreas de conhecimento, puderem contribuir, cada uma com sua especificidade, para o estudo comum de problemas concretos ou para o desenvolvimento de projetos de investigação e/ou de ação. Enfatizam que o currículo deve ter tratamento metodológico que evidencie a interdisciplinaridade e a contextualização (BRASIL, 2013, p. 30).

Segundo Japiassu (1976), a interdisciplinaridade caracteriza-se pela intensidade das trocas entre os especialistas e pelo grau de integração real das disciplinas no interior de um mesmo projeto. Para Freire (2011), a interdisciplinaridade refere-se a uma prática de construção do conhecimento pelo sujeito com base em sua relação com o contexto, com a realidade e com a cultura nos quais está inserido. Ela busca responder à necessidade de superação da visão fragmentada nos processos de produção e socialização do conhecimento (THIESEN, 2008).

O resultado da fragmentação e da disciplinaridade do conhecimento é a perda de sentido que se manifesta nos discentes como repúdio por esta ou aquela disciplina, demonstrando que os mesmos não conseguem perceber as ligações entre diferentes conteúdos ou entre estes e as questões do cotidiano em que vivem, e as semelhanças e relações entre as diferentes áreas do conhecimento. Essa falta de correlação entre os conhecimentos tratados na escola contribui para o desinteresse pelos estudos sendo prejudicial à aprendizagem dos estudantes que se tornam incapazes de pensar globalmente sobre algum problema (GERHARD, 2010).

O ensino de Física é considerado complexo e entediante pela maioria dos estudantes, provavelmente, porque desenvolveram um preconceito de que a disciplina caracteriza-se por cálculos abstratos trabalhados de modo distante de um contexto facilitador da compreensão (MENEGOTTO; ROCHA FILHO, 2008). Assim, torna-se necessário encontrar formas de despertar o interesse dos alunos, tornando a disciplina de Física mais compreensível e mais próxima da vivência desses discentes (NASCIMENTO, 2015), o que, possivelmente, poderia ser alcançado pela 


\section{Eithrapẫ

ISSN: 1984-6444 | http://dx.doi.org/10.5902/1984644443675

utilização de uma metodologia interdisciplinar que estabeleça uma ponte entre os vários conhecimentos e também com o cotidiano.

Desta forma, o presente trabalho teve por finalidade verificar a influência do estilo de aprendizagem dos discentes em seu desempenho acadêmico nas disciplinas de Biologia e Física, comparando-o com o estilo dos docentes das referidas disciplinas. Além disso, verificar se a interdisciplinaridade, através de uma sequência didática, pode contribuir para uma melhor aprendizagem, segundo a percepção dos discentes.

\section{Metodologia}

\section{Aspectos éticos}

Esta pesquisa foi aprovada pelo Comitê de Ética em Pesquisa da Universidade Federal de Ouro Preto, parecer 3.410.681. Os indivíduos foram informados sobre o objetivo deste estudo e aqueles que aceitaram participar assinaram o Termo de Consentimento Livre e Esclarecido (TCLE). Caso o participante fosse menor de idade, este assinou o Termo de Assentimento Livre e Esclarecido e seus responsáveis, o TCLE.

\section{Desenho do estudo}

Essa pesquisa ocorreu em setembro de 2019 e teve como público-alvo estudantes de uma turma de $2^{\mathrm{a}}$ série de uma instituição profissionalizante da rede federal de ensino. Para avaliação do estilo de aprendizagem e da percepção de interdisciplinaridade dos discentes, foram utilizados dois instrumentos. O primeiro instrumento tratava-se de um questionário contendo vinte questões objetivas para determinar o estilo de aprendizagem dos discentes. Esse questionário foi aplicado antes da realização de uma sequência didática sobre biofísica da respiração, que tinha por finalidade evidenciar a interdisciplinaridade do referido conteúdo. Posteriormente à sequência didática, foi avaliada a percepção de interdisciplinaridade, por meio de um segundo instrumento que utilizava a escala do 


\section{N HEM

ISSN: 1984-6444 | http://dx.doi.org/10.5902/1984644443675

tipo Likert. Os dois instrumentos foram aplicados pelo pesquisador de forma presencial durante aulas das disciplinas de Biologia e Física.

Com o intuito de comparar o estilo de aprendizagem dos discentes com o de seus professores de Biologia e Física, o questionário sobre estilo de aprendizagem também foi aplicado aos dois docentes.

\section{Instrumentos utilizados}

\section{Instrumento para identificação do estilo de aprendizagem}

O questionário sobre estilo de aprendizagem apresentava vinte questões que compõem o teste denominado New Index of Learning Styles (N-ILS) proposto por Vieira-Júnior (2012) e refletem as quatro dimensões do modelo de aprendizagem de Felder e Silverman (1988). Essas dimensões representam as etapas da aprendizagem, sendo que, em cada dimensão, existem dois polos. Dependendo da maneira como o estudante aprende, ele tende a um dos polos. As dimensões e seus respectivos polos são: (i) Percepção, na qual o estudante tende a ser sensorial (gosta de fatos, dados e experiências) ou intuitivo (prefere princípios e teorias); (ii) Entrada, que pode ser visual (os alunos relembram melhor o que vêem: imagens, filmes, diagramas e demonstrações) ou verbal (preferem explicações verbais a demonstrações visuais); (iii) Processamento, na qual o aluno tende a ser ativo (não aprende muito em situações que o obrigue a ser passivo como nas aulas expositivas) ou reflexivo (aprende muito em situações que Ihe ofereça oportunidade para pensar a respeito da informação que está sendo apresentada); e (iv) Entendimento, que pode ser sequencial (segue um processo de raciocínio linear para resolver problemas) ou global (faz um salto intuitivo) (CURY, 2000; VIEIRA JÚNIOR, 2012). A dimensão Percepção corresponde ao momento em que o discente é apresentado a um novo conteúdo, sendo avaliada por perguntas como, por exemplo, "Acho mais fácil aprender: a partir de experimentos ou a partir de conceitos". A dimensão Entrada é considerada como uma "recepção" do novo conteúdo, possuindo perguntas tais como "Relembro melhor: o que vejo ou o que ouço". A dimensão Processamento representa a fase na qual o estudante faz 


\section{Autนaดูลิ}

ISSN: 1984-6444 | http://dx.doi.org/10.5902/1984644443675

análises e inferências e é avaliada no N-ILS por perguntas como "Eu prefiro estudar: em grupo ou sozinho". Por último, no N-ILS, uma das perguntas que avaliam a dimensão Entendimento é "Eu aprendo: num ritmo constante, etapa por etapa, ou em saltos (fico confuso por algum tempo e, repentinamente, tenho um "estalo")".

Para identificação do estilo de aprendizagem, todas as dimensões foram avaliadas por cinco perguntas. A identificação do polo e sua intensidade (preferência fraca, moderada e forte) em cada dimensão foi resultado da combinação entre as respostas das cinco questões, sendo que, em um dos polos, as questões são pontuadas positivamente e, no outro, negativamente. Quando o discente responde todas as cinco questões referentes a um polo de uma dimensão, ele apresenta preferência forte por aquele polo (escore 5); caso responda quatro questões de um polo e uma de outro, há uma preferência moderada pelo primeiro (escore 3); e, caso responda três questões de um dos polos e duas do outro, a preferência será fraca pelo primeiro, sendo o escore 1 (Ex: um estudante respondeu 3 perguntas marcando a opção de polo reflexivo e 2 de polo ativo, assim, este discente tem preferência fraca pelo polo reflexivo).

Sendo assim, baseando-se na pontuação obtida do N-ILS, caso o escore na escala tenha sido, 1 em cada dimensão, há um equilíbrio quanto às preferências de aprendizagem. Caso o escore tenha sido 3 , existe uma preferência moderada por um dos polos da escala e este discente pode aprender mais facilmente, caso o ambiente de ensino favoreça o referido polo. $E$, no caso de um escore 5 , significa uma forte preferência por um dos polos, podendo o estudante ter dificuldade de aprendizagem, caso essa preferência não seja favorecida (PEREIRA; VIEIRAJÚNIOR, 2013). O estilo de aprendizagem geral da turma foi comparado ao estilo de aprendizagem dos docentes responsáveis pelas disciplinas de Biologia e Física e com o percentual de discentes em recuperação nas referidas disciplinas.

\section{Instrumento para avaliação da percepção da interdisciplinaridade}

A análise da percepção da interdisciplinaridade ocorreu por meio da aplicação de um instrumento utilizando a escala de Likert, que atribui graus de concordância a 


\section{Autนaดูลิ}

ISSN: 1984-6444 | http://dx.doi.org/10.5902/1984644443675

diferentes afirmações (LIKERT, 1932). Esse instrumento foi constituído de três blocos de afirmativas, de modo que cada um deles se refere a um tema que dialoga com os objetivos da pesquisa (constructos).

O primeiro bloco analisou a compreensão de Ciências por meio de atividades interdisciplinares. Esse bloco possuía afirmativas como "Conteúdos trabalhados de forma interdisciplinar ajudam a identificar os fenômenos físicos do dia-a-dia". O segundo, analisou o interesse pela Física e Biologia por meio de atividades interdisciplinares. Uma afirmativa desse bloco foi "As atividades interdisciplinares realizadas despertam mais o interesse pela Física que aulas tradicionais". Já o terceiro, analisou as aulas práticas como meio de aprendizado. Um exemplo de afirmativa deste terceiro bloco foi "Aulas práticas facilitam a compreensão do funcionamento do corpo humano".

Para cada afirmativa dentro dos constructos o entrevistado teve cinco opções de resposta baseadas no seu grau de concordância sendo estas: 1 - discordo totalmente, 2 - Discordo parcialmente, 3 - Meus argumentos para discordar e concordar são equivalentes, 4 - Concordo parcialmente, 5 - Concordo totalmente.

E, um quarto bloco de perguntas dissertativas sobre o feedback dos discentes quanto às atividades interdisciplinares realizadas na sequência didática. Uma destas perguntas foi "Para você as atividades interdisciplinares auxiliaram na compreensão da Física e da Biologia? Por quê?"

\section{Elaboração e aplicação de uma sequência didática}

Uma sequência didática foi elaborada e aplicada pelo pesquisador, visando evidenciar a interdisciplinaridade entre Biologia e Física no conteúdo referente ao sistema respiratório. Essa sequência didática foi aplicada em seis aulas de 50 minutos e constituiu-se das seguintes etapas sequenciais:

(i) aula expositiva e dialogada. Durante essa aula foi abordado o referido conteúdo de Biologia mostrando a interface do seu funcionamento (movimentos de inspiração e expiração) com assuntos estudados na disciplina de Física, como a Lei dos Gases que explicam seu comportamento; 


\section{Autนaดูลิ}

ISSN: 1984-6444 | http://dx.doi.org/10.5902/1984644443675

(ii) exibição de um vídeo sobre o sistema respiratório da Discovery Channel que proporcionou uma visão geral do assunto;

(iii) atividade prática referente à construção de um protótipo do pulmão humano. Essa atividade foi realizada no laboratório de Física da instituição sendo a turma dividida em grupos de cinco alunos. Ao final dessa atividade, os estudantes foram orientados a movimentar as partes do protótipo simulando os movimentos de inspiração e expiração e comparando-os ao comportamento dos gases estudado na Física. Isso possibilitou observar o deslocamento dos gases e atestar a relação existente entre as grandezas físicas volume e pressão;

(iv) uma simulação sobre o comportamento dos gases realizada na plataforma $P h E T$ Interactive Simulations da Universidade do Colorado (2017). Para essa simulação, os discentes utilizaram computadores do laboratório de Física. Durante toda a realização da simulação os discentes foram orientados a compará-la ao funcionamento do pulmão nos processos de inspiração e expiração;

(v) uma gincana educativa utilizando o aplicativo de leitura de código QR (Quick response). Cada código representava uma pergunta relacionada ao conteúdo abarcado na sequência didática. Para essa atividade, a turma foi dividida em grupos, proporcionando o trabalho em equipe.

Conforme descrito, durante a sequência didática foram realizadas atividades variadas, tendo em vista os polos de cada dimensão do aprendizado. Os discentes tiveram a experiência de fazer trabalhos em grupo (polo ativo) e individuais (polo reflexivo). As explanações do assunto foram escritas e faladas (polo verbal), mas também foram compostas por várias figuras, além da apresentação de vídeo e demonstração pela simulação $P h E T$ (polo visual). E, por fim, o conteúdo foi apresentado em etapas progressivamente complexas favorecendo o aprendizado dos discentes sequenciais. No entanto, especialmente nas atividades práticas, os estudantes tinham a visão global do conteúdo, o que favoreceu também aqueles que fossem globais. 


\section{-

ISSN: 1984-6444 | http://dx.doi.org/10.5902/1984644443675

\section{Análise de dados}

Os dados obtidos através da aplicação dos dois instrumentos foram duplamente digitados no software EpiData 3.1 e, após correção das divergências de digitação, exportados e analisados no programa Excel. A identificação do estilo de aprendizagem dos participantes foi feita conforme descrito acima e o resultado expresso em frequência absoluta e relativa.

Para avaliação do instrumento sobre percepção de interdisciplinaridade (escala de Likert), foi realizada uma análise descritiva da frequência relativa de cada afirmativa. Já as suas perguntas dissertativas foram avaliadas através de uma análise textual discursiva.

\section{Resultados e Discussão}

\section{Caracterização dos participantes}

A turma estudada era composta de 32 discentes, 20 (62,5\%) do sexo feminino e $12(37,5 \%)$ do sexo masculino. Os estudantes possuíam idade média de 16,4 anos (desvio padrão, 0,6 anos). Em relação aos docentes, um deles é do sexo masculino e o outro feminino, tendo um 36 e o outro 40 anos.

\section{Estilo de aprendizagem de discentes e professores}

Todos os 32 discentes da turma responderam o questionário sobre estilo de aprendizagem. A Tabela 1 mostra os resultados referentes ao estilo de aprendizagem dos participantes desse estudo. 


\section{Eltha \\ ISSN: $1984-6444$

ISSN: 1984-6444 | http://dx.doi.org/10.5902/1984644443675

Tabela 1 - Estilo de aprendizagem dos discentes e docentes.

\begin{tabular}{ccccc|c|c|c|c}
\hline \multirow{2}{*}{ Polos } & & \multicolumn{7}{c}{ Preferência } \\
& Participantes & Forte & Moderada & Fraca & Fraca & Moderada & Forte & \multirow{2}{*}{ Polos } \\
& & $\mathbf{n}(\%)$ & $\mathbf{n}(\%)$ & $\mathbf{n}(\%)$ & $\mathbf{n}(\%)$ & $\mathbf{n}(\%)$ & $\mathbf{n}(\%)$ & \\
\hline Sensorial $^{1}$ & Discentes & $8(25,0)$ & $16(50,0)$ & $8(25,0)$ & - & - & - & Intuitivo $^{1}$ \\
& Docentes & - & - & $2(100)$ & - & - & - & \\
\multirow{2}{*}{ Visual $^{2}$} & Discentes & $4(12,5)$ & $12(37,5)$ & $10(31,3)$ & $5(15,6)$ & - & $1(3,1)$ & Verbal $^{2}$ \\
& Docentes & $1(50,0)$ & $1(50,0)$ & - & - & - & - & \\
Ativo $^{3}$ & Discentes & $4(12,5)$ & $7(21,9)$ & $5(15,6)$ & $9(28,1)$ & $4(12,5)$ & $3(9,4)$ & Reflexivo $^{3}$ \\
& Docentes & - & - & $1(50,0)$ & $1(50,0)$ & - & - & \\
Sequencial $^{4}$ & Discentes & $2(6,2)$ & $11(34,4)$ & $9(28,1)$ & $4(12,5)$ & $3(9,4)$ & $3(9,4)$ & Global $^{4}$ \\
& Docentes & - & $1(50,0)$ & $1(50,0)$ & - & - & - & \\
\hline
\end{tabular}

1 Dimensão percepção; 2 Dimensão entrada; 3 Dimensão processamento; 4 Dimensão entendimento.

Fonte: elaborado pelos autores (2019).

Em relação à dimensão "Percepção", observou-se que todos os discentes têm tendência ao polo sensorial, sendo que 25,0\% tem preferência forte, 50,0\% moderada e 25,0\%, leve (Tabela 1). Ao polo sensorial pertencem indivíduos que gostam de aprender fatos e experiências e que, desta forma, preferem que o conteúdo seja apresentado de maneira mais detalhada (passo-a-passo), com conexão com o dia-a-dia (mostrando dados resultantes de experimentos e/ou casos reais) e, ainda, incitando os sentidos (utilizando vídeos, animações, etc.) (VIEIRA JÚNIOR, 2012; PEREIRA; VIEIRA-JÚNIOR, 2013). Portanto, esses discentes podem ter maior facilidade de aprendizado caso $o$ ambiente de ensino favoreça esse polo. $E$ isso pode ser comprovado pelas respostas discursivas dos discentes à questão "O que você gostou nas atividades realizadas sobre o sistema respiratório?" se referindo às atividades práticas. Ainda nessa questão, os estudantes identificados como E1, E2 e E3 responderam, respectivamente: "Montar o sistema respiratório, fazer a simulação no computador"; "As simulações e experimentos"; e "as atividades práticas e os vídeos ajudaram a entender a matéria", mostrando que, realmente, a turma avaliada gosta de aprender através de experiências que evidenciem uma conexão com o seu cotidiano. 


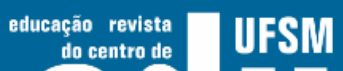 Eulloaral}

ISSN: 1984-6444 | http://dx.doi.org/10.5902/1984644443675

Outro aspecto interessante a ressaltar é que, no primeiro ano do ensino técnico integrado da instituição em questão, fazendo parte da grade curricular, os estudantes têm aulas práticas na disciplina de Física, o que, talvez, tenha contribuído para o desenvolvimento do polo sensorial desses alunos. Sabe-se que cada indivíduo enfoca a aprendizagem de uma forma peculiar, fruto da herança, experiências anteriores e também de exigências atuais do ambiente em que se encontra (BARROS, 2008).

Para a dimensão "Entrada", foi verificado 81,3\% dos discentes têm tendência ao polo visual. Apenas um estudante $(3,1 \%)$ tem preferência forte pelo polo verbal e outros $5(15,6 \%)$ têm preferência leve também pelo polo verbal (Tabela 1). Desse modo, a maioria da turma relembra melhor o que vê - figuras, diagramas, fluxogramas, filmes e demonstrações (PEREIRA; VIEIRA-JÚNIOR, 2013) - e uma metodologia de aulas, por meio da qual os conceitos sejam exemplificados e aprofundados visualmente, facilitaria o aprendizado.

A terceira dimensão "Processamento" abrange os polos ativo e reflexivo. Indivíduos considerados ativos tendem a compreender e reter melhor a informação trabalhando de modo ativo - discutindo ou aplicando a informação ou explicando-a para outros. Gostam de trabalhar em grupo e de participar das aulas. Já indivíduos reflexivos preferem primeiramente refletir quietamente sobre a informação e trabalhar sozinhos (PEREIRA; VIEIRA-JÚNIOR, 2013). Nessa dimensão, a turma avaliada apresenta-se com $50 \%$ dos discentes com preferência ao polo ativo e a outra metade, ao polo reflexivo, em graus variados de preferência (Tabela 1).

Na última dimensão "Entendimento", foi observado que mais da metade da turma $(68,7 \%)$ tem tendência ao polo sequencial (Tabela 1). Os indivíduos pertencentes a esse polo tendem a aprender de forma linear, em etapas logicamente sequenciadas (PEREIRA; VIEIRA-JÚNIOR, 2013) e sua aprendizagem é favorecida quando o conteúdo é apresentado com atividades progressivamente complexas (VIEIRA JÚNIOR, 2012). O restante 31,3\% tem preferência pelo polo global, e destes, 12,5\% tem preferência leve (Tabela 1). Nesse polo, os estudantes tendem a aprender em grandes saltos, assimilando o material quase aleatoriamente, sem ver as conexões, para, então, repentinamente "compreender" tudo (PEREIRA; VIEIRA- 


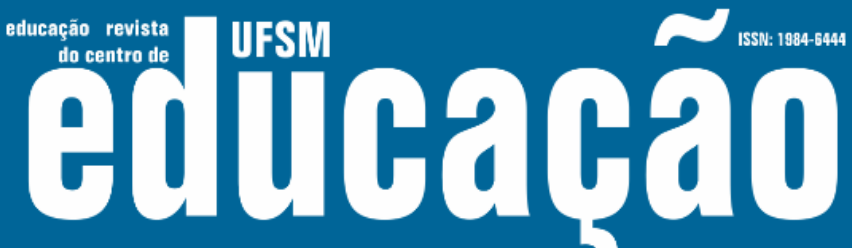

ISSN: 1984-6444 | http://dx.doi.org/10.5902/1984644443675

JÚNIOR, 2013). Desse modo, um ambiente de ensino no qual o conteúdo seja apresentado por grandes etapas, de forma a analisar primeiro o todo e depois os detalhes específicos (VIEIRA JÚNIOR, 2012), favoreceria o aprendizado.

As atividades da sequência didática deste estudo foram elaboradas buscando contemplar todos os polos de cada dimensão do aprendizado. Dessa forma, essa abordagem diversificada do conteúdo permitiu atender a variados estilos de aprendizagem e despertou o interesse da turma, potencializando o aprendizado. Isso pode ser comprovado pela resposta de vários estudantes à questão "O que você não gostou nas atividades realizadas sobre o sistema respiratório?" como E4 "Gostei de todas atividades"; E5 "Nada"; E6 "Gostei de tudo"; E7 "Não tenho nada a reclamar, pois gostei de tudo"; E8 "Na minha opinião, não houve ponto negativo"; E9 "Nada, gostei muito de tudo".

Em resumo, a turma estudada é predominantemente sensorial/visual/ativo e reflexivo/sequencial.

Determinou-se também o estilo de aprendizagem dos professores das disciplinas Física e Biologia, pois quando há concordância entre os estilos de aprendizagem de professores e alunos o aprendizado pode se tornar facilitado. Foi observado que o estilo de aprendizagem do docente de Biologia é sensorial (preferência fraca); visual (preferência moderada); ativo (preferência fraca) e sequencial (preferência fraca). E, o do docente de Física, é sensorial (preferência fraca); visual (preferência forte); reflexivo (preferência fraca) e sequencial (preferência moderada).

Então, comparando-se o estilo de aprendizagem global da turma (sensorial/visual/ativo e reflexivo/sequencial) com o de seus professores, nota-se uma concordância entre estes, o que tende a favorecer a aprendizagem. Apesar de se saber que o aprendizado pode ocorrer sem que o estilo de aprendizagem de um indivíduo seja plenamente atendido, a velocidade e qualidade dessa aprendizagem podem ser potencializadas quando o ambiente, os métodos e os recursos utilizados são complementares ao estilo de aprendizagem (VALENTE; ABIB; KUSNIK, 2007).

Os estilos de aprendizagem relacionam-se à história de vida do indivíduo enquanto aprendiz. Cada pessoa concebe determinada ciência a partir de sua 


\section{Autharão}

ISSN: 1984-6444 | http://dx.doi.org/10.5902/1984644443675

experiência como aluno, do conhecimento construído, da opinião de seus mestres e também da influência sócio-cultural que teve, sendo esse arcabouço uma filosofia própria e única já que não existem dois indivíduos com vivências iguais. Essas concepções influenciam a prática pedagógica dos professores (CURY, 2000).

Nessa perspectiva, a identificação dos estilos de aprendizagem em uma turma permite ao docente uma adequação das suas estratégias de ensino. No entanto, é importante que o professor considere essa individualidade e a heterogeneidade e ajuste a forma de ministrar os conteúdos, a fim de contemplar os vários estilos de aprendizagem encontrados em suas turmas e não apenas o estilo predominante. Além disso, a variação da metodologia de ensino possibilita, também, o desenvolvimento de outras habilidades e competências nos discentes e a promoção da experimentação de novos estilos nos alunos, trabalhando aqueles menos predominantes. Uma vez que os estilos são flexíveis e são tendências podendo modificar-se ou não ao longo da vida do indivíduo, conhecê-los possibilita ampliar as capacidades dos indivíduos para que a aprendizagem seja um ato motivador, fácil, comum e cotidiano (BARROS, 2008; BARROS, 2014; GOMES et al., 2018). Atender somente ao estilo de aprender preferido dos estudantes pode comprometer a aquisição da amplitude mental necessária para alcançar o máximo potencial em seu desenvolvimento, o que pode dificultar o seu desempenho profissional futuro, frente às variadas situações cotidianas ou exigências do trabalho (LOPES, 2002).

Segundo Kolb e Kolb (2005), a definição dos estilos beneficia também os discentes, auxiliando-os a avaliar seus pontos fortes e, a partir disso, explorá-los com maior ênfase com vistas ao aperfeiçoamento do seu aprendizado. Também, a partir da identificação dos estilos de aprendizagem, abre-se a possibilidade de um esforço conjunto entre docentes e instituição no intuito de buscar mecanismos para facilitar o processo de ensino e aprendizagem e que contribuam, dessa forma, para melhorar a conectividade e adaptabilidade entre docentes e discentes (LIZOTE et al., 2019). 


\section{$=$

ISSN: 1984-6444 | http://dx.doi.org/10.5902/1984644443675

\section{Estilo de aprendizagem de discentes $\mathrm{x}$ recuperação}

Foi observado que 12 discentes não ficaram em recuperação, enquanto os outros 20 ficaram em recuperação em Biologia ou Física na primeira etapa acadêmica do ano letivo de 2019. Ao comparar o estilo de aprendizagem dos estudantes que não ficaram em recuperação (Tabela 2) com o daqueles que ficaram (Tabela 3), observou-se que as maiores diferenças encontram-se nas dimensões "Processamento" e "Entendimento". Para a dimensão "Processamento", não houve, entre os discentes que não ficaram em recuperação, nenhum que tenha preferência forte pelo polo ativo e nem pelo polo reflexivo, ao contrário do grupo dos discentes que ficaram em recuperação, no qual 35\% tinham preferência forte ou pelo polo ativo $(20 \%)$ ou pelo polo reflexivo (15\%). Entretanto, é na dimensão "Entendimento" que foi verificada a maior diferença entre os dois grupos de maneira que, no grupo de discentes que não ficaram em recuperação, nenhum destes tinham preferência pelo polo global sendo todos sequenciais. Já no grupo em recuperação, 50\% dos estudantes têm preferência pelo polo global, sendo $30 \%$ uma preferência moderada a forte, o que é discordante em relação ao estilo de aprendizagem de seus professores, que são sequenciais. Certamente, essa discordância teve algum impacto no aprendizado desses estudantes, dificultando o entendimento do conteúdo ministrado. As Tabelas 2 e 3, a seguir, mostram esses resultados. 


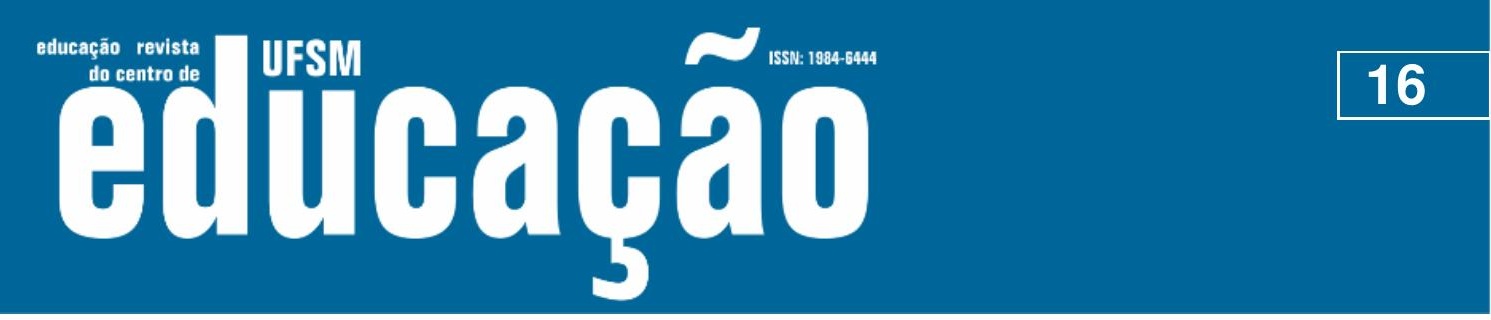

ISSN: 1984-6444 | http://dx.doi.org/10.5902/1984644443675

Tabela 2 - Estilo de aprendizagem dos discentes que não ficaram em recuperação em Biologia ou Física e de seus professores dessas disciplinas.

\begin{tabular}{|c|c|c|c|c|c|c|c|c|}
\hline \multirow{3}{*}{ Polos } & \multirow{3}{*}{ Participantes } & \multicolumn{6}{|c|}{ Preferência } & \multirow{3}{*}{ Polos } \\
\hline & & Forte & Moderada & Fraca & Fraca & Moderada & Forte & \\
\hline & & n (\%) & n (\%) & n (\%) & n (\%) & n (\%) & n (\%) & \\
\hline \multirow[t]{2}{*}{ Sensorial ${ }^{1}$} & Discentes & $4(33,3)$ & $6(50,0)$ & $2(16,7)$ & - & - & - & Intuitivo ${ }^{1}$ \\
\hline & Docentes & - & - & $2(100)$ & - & - & - & \\
\hline \multirow[t]{2}{*}{ Visual $^{2}$} & Discentes & $2(16,7)$ & $4(33,3)$ & $4(33,3)$ & $2(16,7)$ & - & - & Verbal $^{2}$ \\
\hline & Docentes & $1(50,0)$ & $1(50,0)$ & - & - & - & - & \\
\hline \multirow[t]{2}{*}{ Ativo $^{3}$} & Discentes & - & $2(16,7)$ & $2(16,6)$ & $6(50,0)$ & $2(16,7)$ & & Reflexivo ${ }^{3}$ \\
\hline & Docentes & - & - & $1(50,0)$ & $1(50,0)$ & - & - & \\
\hline \multirow[t]{2}{*}{ Sequencial $^{4}$} & Discentes & $1(8,3)$ & $7(58,3)$ & $4(33,4)$ & - & - & - & Global $^{4}$ \\
\hline & Docentes & - & $1(50,0)$ & $1(50,0)$ & - & - & - & \\
\hline
\end{tabular}

1 Dimensão percepção; 2 Dimensão entrada; 3 Dimensão processamento; 4 Dimensão entendimento.

Fonte: elaborado pelos autores (2019).

Tabela 3 - Estilo de aprendizagem dos discentes que ficaram em recuperação em Biologia ou Física e de seus professores dessas disciplinas.

\begin{tabular}{|c|c|c|c|c|c|c|c|c|}
\hline \multirow{3}{*}{ Polos } & \multirow{3}{*}{ Participantes } & \multicolumn{6}{|c|}{ Preferência } & \multirow{3}{*}{ Polos } \\
\hline & & & Moderada & Fraca & Fraca & Moderada & & \\
\hline & & n (\%) & n (\%) & n (\%) & n (\%) & n (\%) & n (\%) & \\
\hline \multirow[t]{2}{*}{ Sensorial ${ }^{1}$} & Discentes & $4(20,0)$ & $10(50,0)$ & $6(30,0)$ & - & - & - & Intuitivo ${ }^{1}$ \\
\hline & Docentes & - & - & $2(100)$ & - & - & - & \\
\hline \multirow[t]{2}{*}{ Visual $^{2}$} & Discentes & $2(10,0)$ & $8(40,0)$ & $6(30,0)$ & $3(15,0)$ & - & $1(5,0)$ & Verbal $^{2}$ \\
\hline & Docentes & $1(50,0)$ & $1(50,0)$ & - & - & - & - & \\
\hline \multirow[t]{2}{*}{ Ativo $^{3}$} & Discentes & $4(20,0)$ & $5(25,0)$ & $3(15,0)$ & $3(15,0)$ & $2(10,0)$ & $3(15,0)$ & Reflexivo $^{3}$ \\
\hline & Docentes & - & - & $1(50,0)$ & $1(50,0)$ & - & - & \\
\hline \multirow[t]{2}{*}{ Sequencial $^{4}$} & Discentes & $1(5,0)$ & $4(20,0)$ & $5(25,0)$ & $4(20,0)$ & $3(15,0)$ & $3(15,0)$ & Global $^{4}$ \\
\hline & Docentes & - & $1(50,0)$ & $1(50,0)$ & - & - & - & \\
\hline
\end{tabular}

1 Dimensão percepção; 2 Dimensão entrada; 3 Dimensão processamento; 4 Dimensão entendimento.

Fonte: elaborado pelos autores (2019). 


\section{Authaดูã}

ISSN: 1984-6444 | http://dx.doi.org/10.5902/1984644443675

O conhecimento da forma como cada discente apropria-se do saber, ou seja, do seu estilo de aprendizagem, permite construir diretrizes de como elaborar estratégias que tornem a metodologia de ensino algo que contemple a diversidade na forma de aprendizagem, tentando, assim, garantir que o aprendizado ocorra independente das variáveis que possam estar presentes em seu entorno (BARROS, 2014). Nesse sentido, o estudo sobre os estilos de aprendizagem pode ter reflexos educacionais benéficos para alunos e professores na condução do processo ensinoaprendizagem (SCHMITT; DOMINGUES, 2016), além de favorecer o autoconhecimento.

Sabe-se que a técnica de ensino utilizada por um professor necessita estar em consonância com o contexto do discente, a fim de não se tornar inadequada. Dessa forma, ao escolher uma metodologia de ensino, o docente precisa estar atento tanto à necessidade educativa dos seus alunos como ao seu contexto social, cultural, político e econômico, de modo a favorecer a aprendizagem (BARROS, 2014). Isso porque a concordância entre o estilo de aprendizagem do professor e o de seus alunos refletindo na prática pedagógica do docente é apenas um dos fatores que influenciam o desempenho escolar. Também o tipo de avaliação e o relacionamento entre alunos e professor podem influenciar no desempenho (CAVALCANTE; SANTOS JÚNIOR, 2013).

Finalmente, cumpre ressaltar que os fatores que influenciam a proficiência são múltiplos e complexos, perpassando desde as características socioeconômicas e culturais dos indivíduos e de suas famílias até as dinâmicas que ocorrem nas salas de aula, entre professores e estudantes, e as características estruturais da escola (PALERMO; SILVA; NOVELLINO, 2014). Os estilos de aprendizagem são participantes diretos no processo de ensino; entretanto, este é extremamente complexo e não se restringe à aquisição de conhecimentos, envolvendo inúmeras variáveis que se combinam de diferentes formas e estão sujeitas à influência de fatores externos, internos, individuais e sociais (LOPES, 2002). 


\section{usm eltiogato

ISSN: 1984-6444 | http://dx.doi.org/10.5902/1984644443675

\section{Percepção sobre interdisciplinaridade}

O instrumento para avaliar a percepção de interdisciplinaridade (escala de Likert) foi respondido por 27 discentes, 16 (59,3\%) do sexo feminino e $11(40,7 \%)$ do sexo masculino. A Tabela 4 mostra os resultados.

Tabela 4 - Percepção de interdisciplinaridade dos discentes.

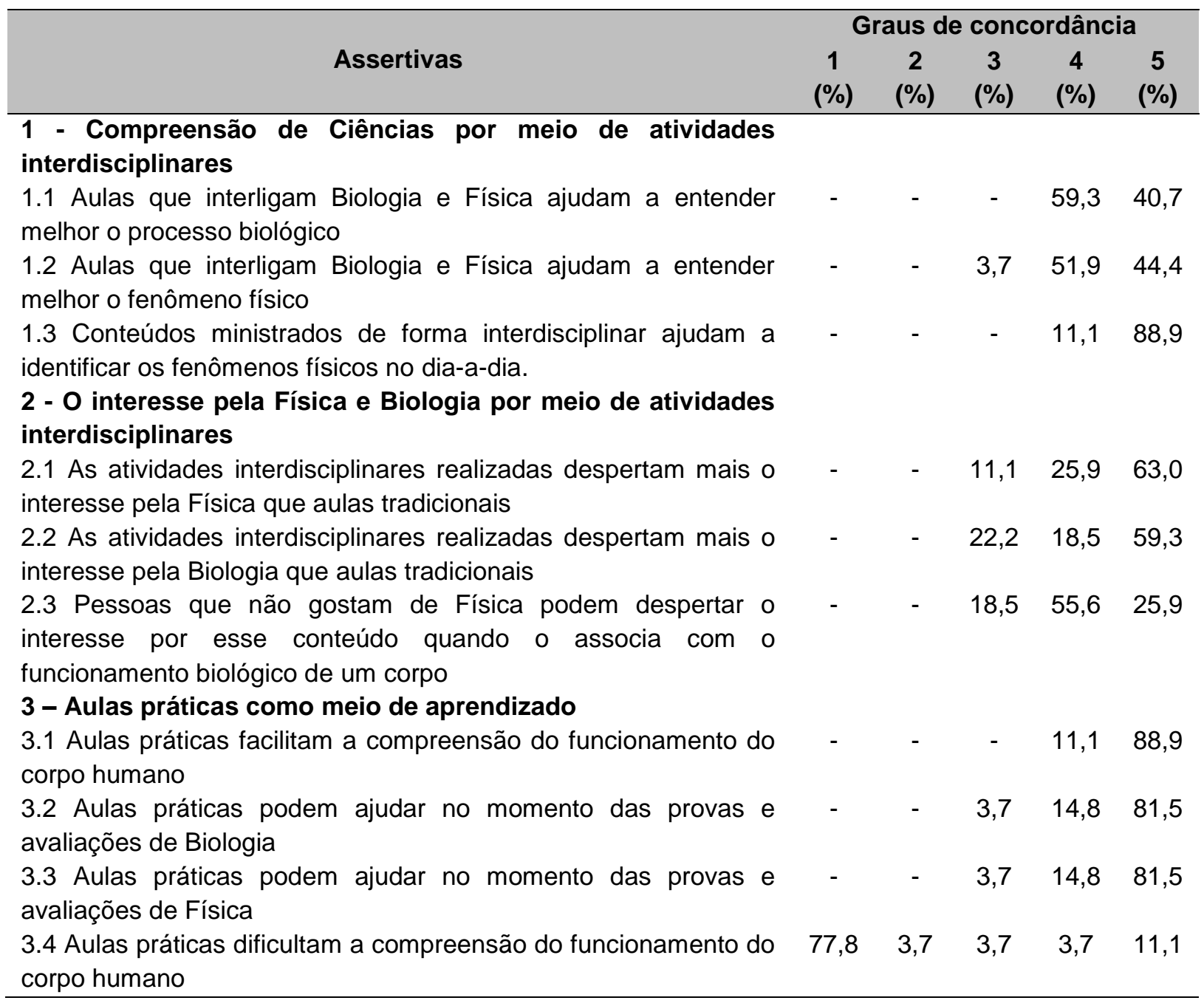

1 - Discordo totalmente, 2- Discordo parcialmente, 3 - Meus argumentos para discordar e concordar são equivalentes, 4 - Concordo parcialmente, 5 - Concordo totalmente Fonte: elaborado pelos autores (2019).

No primeiro constructo, referente à "Compreensão de Ciências por meio de atividades interdisciplinares", foi verificado que $88,9 \%$ dos discentes concordam 


\section{Fusm Ellloahao}

ISSN: 1984-6444 | http://dx.doi.org/10.5902/1984644443675

totalmente com a afirmativa "Conteúdos trabalhados de forma interdisciplinar ajudam a identificar os fenômenos físicos no dia-a-dia" e o restante, 11,1\%, concordam parcialmente com a afirmativa. Para a afirmativa "Aulas que interligam a Biologia e a Física ajudam a entender melhor o processo biológico", 59,3\% da totalidade de estudantes concordam parcialmente e 40,7\% concordam totalmente . E, para a afirmativa "Aulas que interligam a Biologia e a Física ajudam a entender melhor o fenômeno físico", $96,3 \%$ dos entrevistados concordam parcialmente $(51,9 \%)$ ou totalmente $(44,4 \%)$. Apenas um $(3,7 \%)$ discente respondeu que seus argumentos para discordar e concordar eram equivalentes (Tabela 4). É possível verificar, assim, que a maior parte dos discentes considera que as atividades interdisciplinares facilitam a compreensão tanto da Biologia quanto da Física e a identificação, particularmente, dos fenômenos físicos na sua vida cotidiana. Corroborando com estes resultados, na análise textual discursiva das respostas dos discentes à pergunta "Para você, as atividades interdisciplinares auxiliaram na compreensão da Física e da Biologia? Por quê?", foi possível observar que todos os discentes acharam que as atividades interdisciplinares facilitaram a compreensão e a conexão entre as duas disciplinas conforme pode ser exemplificado por algumas respostas dos estudantes: E10 "Porque ajuda a entender a relação das duas matérias"; E11 "Sim, pois vi que os assuntos se relacionam"; E12 "Sim. Porque foi possível compreender melhor o funcionamento do sistema respiratório e os outros temas abordados"; E13 "Sim, pois é melhor para compreender, e quando é prática (com experimentos, etc) é melhor ainda, pois interagimos, e assim conseguimos aprender mais"; E14 "Sim. Porque fica mais fácil e mais real para a compreensão"; e E15 "Sim. Porque de uma tal maneira deixa mais fácil e mais realista a compreensão".

No constructo "O interesse pela Física e Biologia por meio de atividades interdisciplinares", foi observado que $63,0 \%$ dos entrevistados concordam totalmente com a afirmativa "As atividades interdisciplinares realizadas despertam mais o interesse pela Física que aulas tradicionais" e que $25,9 \%$ concordam parcialmente. Da mesma forma, a maioria dos estudantes, 59,3\%, concorda totalmente e 18,5\% parcialmente com a afirmativa "As atividades interdisciplinares realizadas despertam mais o interesse pela Biologia que aulas tradicionais". A última afirmativa do 


\section{F WEM Eulloargo}

ISSN: 1984-6444 | http://dx.doi.org/10.5902/1984644443675

constructo "Pessoas que não gostam de Física podem despertar o interesse por esse conteúdo quando o associa com o funcionamento biológico de um corpo" teve um percentual de $81,5 \%$ dos estudantes que apresentavam concordância, 55,6\% parcial e 25,9\% total (Tabela 4). Também, nesse segundo tópico, é possível observar que as atividades interdisciplinares despertam o interesse dos discentes, principalmente na Física. Esse resultado mostra que a realização de atividades interdisciplinares nas quais o estudante consiga visualizar a conexão entre conteúdos de disciplinas diferentes pode ser um caminho para tornar a Física, considerada complexa por muitos estudantes, mais atrativa e interessante. A importância da contextualização no ensino de Física também foi observada no estudo de Menegotto e Rocha Filho (2008).

Uma das implicações da interdisciplinaridade no processo de ensino e aprendizagem é que um processo educativo pautado na perspectiva interdisciplinar possibilita visualizar mais claramente o elo entre teoria e prática, contribuindo para uma formação mais crítica, criativa e responsável. O enfoque interdisciplinar auxilia a compreensão das complexas redes conceituais, possibilita maior significado e sentido aos conteúdos de aprendizagem e aproxima o sujeito de sua realidade mais ampla, permitindo uma formação mais consistente (THIESEN, 2008). Entretanto, uma dificuldade na implementação da interdisciplinaridade pelos professores é uma lacuna na sua formação tanto inicial quanto continuada (TERRADAS, 2011).

O último constructo referia-se à percepção de aulas práticas como forma de aprendizado e apresentava quatro afirmativas. Para a primeira afirmativa "Aulas práticas facilitam a compreensão do funcionamento do corpo humano", 100\% dos alunos concordaram total $(88,9 \%)$ ou parcialmente $(11,1 \%)$. A maioria dos discentes $(96,3 \%)$ também concordou total $(81,5 \%)$ ou parcialmente $(14,8 \%)$ com a segunda e terceira afirmativas, respectivamente: "Aulas práticas podem ajudar no momento das provas e avaliações de Biologia" e "Aulas práticas podem ajudar no momento das provas e avaliações de Física". A última afirmativa dizia que "Aulas práticas dificultam a compreensão do funcionamento do corpo humano", sendo que $81,5 \%$ dos estudantes discordam total $(77,8 \%)$ ou parcialmente $(3,7 \%)$ (Tabela 4$)$. Essa última afirmativa foi colocada de forma intencional para validar as informações do 


\section{Autนaดูลิ}

ISSN: 1984-6444 | http://dx.doi.org/10.5902/1984644443675

questionário, mostrando que os entrevistados estavam atentos à leitura e compreensão das assertivas. Esse constructo mostra, assim, a importância das aulas práticas no ensino, uma vez que facilitam a compreensão de um conteúdo e, inclusive, podem auxiliar no desempenho dos discentes nas avaliações de qualquer disciplina.

Um resultado semelhante ao acima descrito foi observado através da análise textual discursiva das respostas dos estudantes ao questionamento sobre "O que você gostou nas atividades realizadas sobre o sistema respiratório?", no qual foi possível verificar que 21 discentes citaram as atividades práticas, conforme exemplificado pelas respostas dos estudantes: E16 "A prática, foi melhor para visualizar melhor o que ocorre"; E17 "A prática, pois ficou mais fácil de visualizar o que estava sendo ensinado"; E18 "Consegui entender bem, com mais facilidade o conteúdo com as aulas práticas"; E19 "tudo, tenho mais facilidade em absorver o conteúdo através das aulas práticas"; e, E20 "Gostei da relação entre física e Biologia para explicar como funciona, e do experimento com o galão".

Sendo assim, observa-se que o estabelecimento de uma relação entre o conteúdo ministrado em aula teórica com a realização das atividades práticas proporcionou a aplicação da teoria estudada em sala de aula e sua aproximação com a vivência cotidiana do estudante tornando o processo de aprendizagem mais estimulante e instigante.

\section{Considerações finais}

Neste estudo foi observado que é de grande relevância o conhecimento pelo professor do estilo de aprendizagem de seus alunos, a fim de prover estratégias pedagógicas mais eficazes. Quando os estilos do professor e discente são concordantes o processo de aprendizagem torna-se mais fácil e prazeroso, melhorando o desempenho acadêmico. Entretanto, é importante salientar que inúmeras variáveis de ordem cultural, social e econômica são também determinantes do desempenho escolar e podem estar relacionadas ao processo de ensino, tornando-o bastante complexo. As atividades interdisciplinares favorecem a 


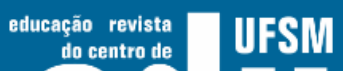 Autthabat

ISSN: 1984-6444 | http://dx.doi.org/10.5902/1984644443675

contextualização dos conteúdos e o diálogo entre as disciplinas. Além disso, a aproximação dos alunos daquilo que é real, utilizando-se atividades práticas, parece ser uma boa alternativa para despertar o seu interesse por conteúdos das várias disciplinas.

Finalmente, é importante que as situações de aprendizagem sejam elaboradas considerando as características dos aprendizes e a sua diversidade. Do contrário, o processo educativo tende a falhar no seu objetivo de proporcionar o aprendizado e o desenvolvimento das habilidades dos estudantes.

Os achados desta pesquisa permitem, assim, uma reflexão sobre como a prática cotidiana dos professores pode contribuir para o aprendizado. Como limitações deste estudo destaca-se que apenas uma turma foi estudada. Além disso, o estilo de aprendizagem foi o único fator avaliado que influencia o desempenho escolar dos alunos. Para pesquisas futuras é importante avaliar um número maior de estudantes e também levar em consideração outros fatores internos e externos à escola que estão diretamente ligados ao sucesso acadêmico.

\section{Referências}

BARROS, Daniela Melaré Vieira. A teoria dos estilos de aprendizagem: convergência com as tecnologias digitais. Revista SER: Saber, Educação e Reflexão, Agudos, v. 1, n. 2, jul./dez. 2008.

BARROS, Daniela Melaré Vieira. Estilos de aprendizagem e as tecnologias: guias didáticos para o ensino fundamental. In: TORRES, Patrícia Lupion. Complexidade: redes e conexões na produção do conhecimento. Curitiba: SENAR - PR., 2014. p. 301-314.

BRASIL. Ministério da Educação. Diretrizes curriculares nacionais da educação básica. Brasília, DF, 2013. Disponível em: http://portal.mec.gov.br/index.php?option=com_docman\&view=download\&alias=1554 8-d-c-n-educacao-basica-nova-pdf\&ltemid=30192. Acesso em: 22 abr. 2020.

CAVALCANTE, Carmem Haab Lutte; SANTOS JUNIOR, Pedro Aureliano dos. Fatores que influenciam o desempenho escolar: a percepção dos estudantes do curso Técnico em Contabilidade do IFRS - Instituto Federal de Educação, Ciência e Tecnologia do Rio Grande do Sul, Campus Porto Alegre. Revista Liberato, Novo Hamburgo, v. 14, n. 21, p. 01-112, jan./jun. 2013. 


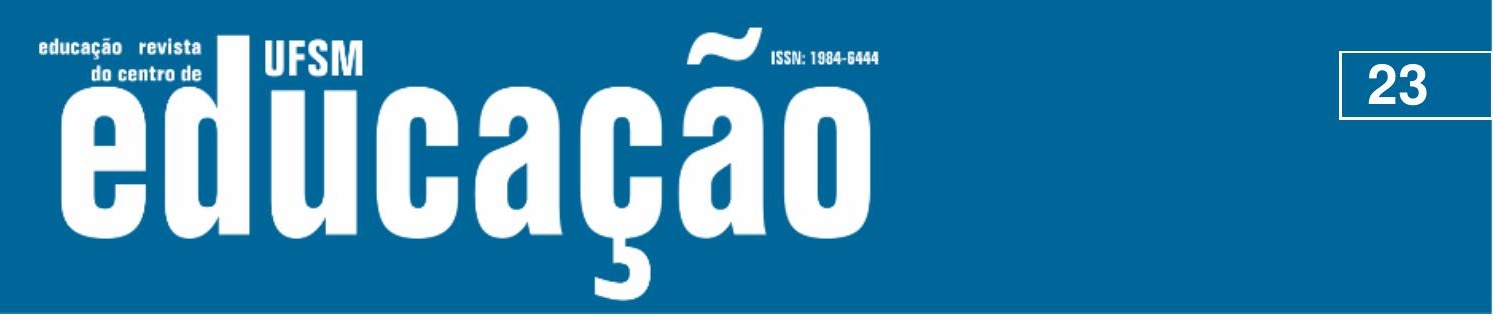

ISSN: 1984-6444 | http://dx.doi.org/10.5902/1984644443675

CURY, Helena Noronha. Estilos de aprendizagem de alunos de Engenharia. Anais do XXVII Congresso Brasileiro de Ensino de Engenharia, Ouro Preto, MG, 2000.

FELDER, Richard Mark; SILVERMAN, Linda Kreger. Learning and teaching styles in engineering education. Journal of Engineering Education, Washington, v. 7, n. 78,

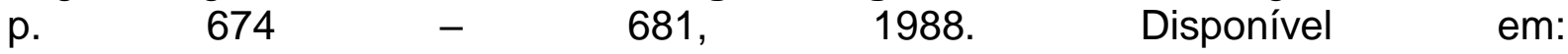
https://pdfs.semanticscholar.org/a100/c5a533d61342b9ce6024023608e7398f9a20.p df. Acesso em: 20 abr. 2020.

FELDER, Richard Mark; SOLOMAN, Barbara A. Index of learning styles questionnaire. North Carolina State University, Raleigh, 1991. Disponível em: https://www.webtools.ncsu.edu/learningstyles/. Acesso em: 21 abr. 2020.

FREIRE, Paulo. Pedagogia do oprimido. 50. ed. Rio de Janeiro: Paz e Terra, 2011.

GERHARD, Ana Cristina. A fragmentação dos saberes na educação científica escolar na percepção de professores de uma escola de ensino médio. 2010. 150p. Dissertação (Mestrado). Pontifícia Universidade Católica do Rio Grande do Sul, Porto Alegre, 2010.

GOMES, Franciene Duarte et al. A perspectiva da relação entre estilos de aprendizagem e a estrutura de mapa conceitual. Perspectivas em Gestão \& Conhecimento, João Pessoa, v. 8, número especial, p. 118-134, out. 2018.

JAPIASSU, Hilton. Interdisciplinaridade e patologia do saber. Rio de Janeiro: Imago, 1976.

KOLB, Alice Y.; KOLB, David Allen. The Kolb Learning Style Inventory-Version 3.1: technical specifications. Boston: LSI Technical Manual, 2005. Disponível em: https://www.researchgate.net/profile/David_Kolb/publication/241157771_The_Kolb_L earning_Style_Inventory-

Version_31_2005_Technical_Specifi_cations/links/555910f508aeaaff3bf98ca9/TheKolb-Learning-Style-Inventory-Version-31-2005-Technical-Specifi-cations.pdf.

Acesso em: 21 abr. 2020.

LIKERT, Rensis. A Technique for the Measurement of Attitudes. New York: Columbia University Press, 1932.

LIZOTE, Suzete Antonieta et al. Estilos de aprendizagem, desempenho acadêmico e avaliação docente. Revista Catarinense da Ciência Contábil, Florianópolis, v. 18, 1-15, e2837, 2019. 


\section{usp

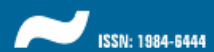

ISSN: 1984-6444 | http://dx.doi.org/10.5902/1984644443675

VIEIRA JUNIOR, Niltom. Planejamento de um ambiente virtual de aprendizagem baseado em interfaces dinâmicas e uma aplicação ao estudo de potência elétrica. 2012. 234f. Tese (Doutorado). Faculdade de Engenharia de Ilha Solteira, Universidade Estadual Paulista, Ilha Solteira, 2012.

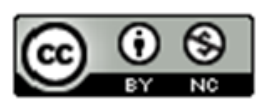

This work is licensed under a Creative Commons Attribution-NonCommercial 4.0 International (CC BY-NC 4.0) 